\title{
Recommendations for Orthotic \& Prosthetic Clinics and Workshops in COVID-19 Pandemic
}

\section{Usama Bin Yar ${ }^{1}$}

\section{Author Info:}

'Department of Orthotics and Prosthetics; Government College University Faisalabad Pakistan

\section{Correspondence:}

Email/Contact:

musamabinyar.14@gmail.com

+092-346-5386368

\section{ABSTRACT}

Orthotics and Prosthetics is an emerging field in medical area for several past years. Recently, COVID-19 is out-breaked as an epidemic and regarding that there is a need of protocols for Orthotic and Prosthetic workplaces to manage against the spread of this disease. Till now, COVID-19 pandemic has given boundless strain on healthcare services providers and assistive technology practitioners, whose defamation is hard to recover. So, it is necessary to remain open to promote health coverage and support to amputees and disables. As only in America there were 1.9 million amputees since 2006 and till now they must have been increased ultimately. Large number of amputees has been increased since few years in recent report of WHO and World Bank. To cater such large number of population, recommendations are suggested which not only covers the introduction to novel coronavirus but also describes the entire frame-work for organizations to regulate themselves in this current epidemic situation. The recommendations accommodate somehow all administrative and management steps with correlation of clinical and non-clinical aspects. Moreover, it emphasizes on quality maintenance, assuring patient support and preventive initiatives regarding COVID-19 pandemic. It is requested to take help from this article and make your efforts to continue to assist people in need during this time.

Keywords: COVID-19, Coronavirus, Clinics, Disability, Orthotics, Prosthetics, Pandemic, Workshops.

\section{Quick Response (QR) Code}

Article Info

Scan Me for Full Text

Received: 2020; Accepted: 30 September 2020;

Published Online: 1 October 2020 How to cite this article in Vancouver Style?

Bin Yar U. Recommendations for Orthotic \& Prosthetic Clinics and Workshops in COVID-19 Pandemic. Europasian J Med Sci. 2020; 2(COVID-19 Special Issue): 93-98. https://doi.org/10.46405/ejms.V2i2.138

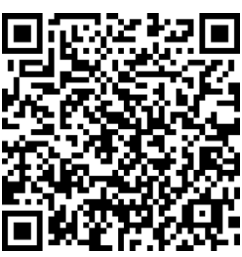

\&. View PDF

\section{Disclaimer}

Conflict of Interest: None Declared;

Source of Support: Nil

Copyright: $(\underset{C}{ } 2020$ by author(s). This is an open access article distributed under the terms of the Creative Commons Attribution International License 4.0 (http://creativecommons.org/licenses/by/4.0/) which permits unrestricted use, distribution, and reproduction in any medium, provided the original work is properly cited.

\section{Publisher's Note}

The Europasian Journal of Medical Sciences (EJMS) (www.europasianjournals.org) is an official Journal of Nirvana Psychosocial Care Center \& Ressearch Institute (www.nirvanapscc.com). The Journal as well as publisher remain neutral with regards to any jurisdictional claims in any published articles, its contents and the institutional affiliations of the authors. 


\section{INTRODUCTION}

Introduction: Coronavirus Disease has emerged world-wide in 2019 and restricted each part of life in all dimensions. It has given a threat not only to human-life but also effected social community, economy, mental-health and globe as a whole, when talking materialistically. It is the third severe respiratory disease when indexed among other diseases such as, SARS-CoV back in 2002 and MERS-CoV in 2012, which intruded and affected the human population in this period of time. ${ }^{1}$

At this time, there are no specific vaccines or treatments for Coronavirus disease, yet work is being done more rapidly than before and simultaneously several trials of vaccines are being conducted to extract the potential one. As on $24^{\text {th }}$ September, 2020, total confirmed cases of COVID-19 were 31,759,233 with 973,904 deaths globally. COVID-19 is more efficient in transmission of infection through human-to-human contact and has less mortality rate when compared to SARS-CoV and MERS-CoV. ${ }^{1}$ Yet we have to take precautions and make a good surveillance arrangements with adequate laboratories to be able to recognize cases and provide efficient public health control. Current efforts are directed towards blocking transmission, isolation, and protection. ${ }^{2}$

Coronavirus has diverted attention by effecting large number of population and subsided other groups with certain liabilities. As, globally there are community of people seeking orthotic and prosthetic services with a variety of impairments, including: brain injuries, spinal cord injuries, cerebral palsy, stroke, burns, amputations etc. These all patients are assessed by orthotists and prosthetists to design and fabricate an assistive device to provide them support or protection to a limb, the torso and the head. Collectively, above all, the goal of rehabilitation is to provide orthotic and prosthetic devices to improve physical performance and gratification. ${ }^{3}$ Whereas, rehabilitation is a necessary procedure to return functionality to limbs. While, orthotists and prosthetists are key members of the clinical rehabilitation team who are responsible for designing and producing orthoses and prostheses to control, compensate and prevent impairment in patients. ${ }^{4}$

Such disables and impaired patients are being ignored behind the wall of COVID-19 pandemic. They are lacking rehabilitation, interventions and most importantly their mobility is being hindered due to isolation and lockdown. The aim of rehabilitation is give quality of life through bridging to disability to physical health, but unfortunately their struggle and improved health is being backpeddling. According to $\mathrm{WHO}$ and World Bank ${ }^{5}$ collaborative report on Disability, discusses that currently in the world there are more than 2 billion people with disabilities, which makes upto $37.5 \%$ of the entire population. On the other-hand, 37.5\% out of $15 \%$ of the world's population, experience physical form of disability. So, it is essential to give attention to this large community of patients as the field of orthotics and prosthetics has no direct interference with medical practitioners to get suffered by COVID-19. Assistive technologist can practice in these crucial days and can serve this community, by opting and implementing the given recommendations.

\section{Recommendation for Workshops and Clinics of Orthotics \& Prosthetics}

The following recommendations are provided on the basis of personal clinical experiences and various clinical inputs, which covers all the clinical and non-clinical aspects. Therefore, these suggestions must be considered as a action against the management of COVID-19 in orthotics and prosthetics, organizations, clinics and workshops. Moreover, can be opt as established protocols.

\section{Administrative Steps}

When we consider patients safety, we are also committed to the safety and health of employees at all level in an organization, specially at this stage of pandemic. Organizational administration should admit and communicate the value of their employees and should prioritize worker's safety and health on the same level as quality of services and products. Secondly, mid-level supervisors should actively contribute in providing health and well-being of employees. Authorities at all degrees of the organization should help to set this tone, as everyone (from managers down to front-line workers) plays an important role in accomplishing required milestone. Thirdly, build accountability into implementation of initiatives as accountability reflects leadership commitment to improved outcomes. Reward them on success in policies, practices, and management approach that is on first priority and rectify or modify initiatives on the basis of established milestones and the results should be monitoring and evaluation. ${ }^{6}$ Following are some recommended steps for administration to act upon, to regulate workplace:

\section{Coronavirus Help or Information Desk:}


- $\mathrm{NIH}^{7}$ recommends for each organization to arrange help desks for COVID-19, where patients/employees can process latest informations or instructions.

\section{Preparedness regarding COVID-19:}

- Arrange an automatic sanitizer bottles and masks at the entrance with a supervisors guiding each patient precisely.

- Use infrared-thermometer at entrance and don't allow patients or employees without checking temperature.

- Ensure accessibility of soaps or hand sanitizer (at least $70 \%$ alcohol).

- Focus on personal hygiene and cleanliness within organization to mitigate COVID-19 transmission and cross-contamination.

\section{During Outbreak of the Disease:}

- Clinicians/ technicians or employees should use masks strictly in the domain.

- Give them a concession who are sick and stand with them, after all they are employees/ clinicians/ technicians of our organization and served under us.

- Avoid using biometric attendance of employees, to avoid recent multiple touching on scanning machine. Moreover, it is suggested to receptionists to maintain manual attendance.

\section{Behavioral and Structural Interventions:}

- $\quad$ See for the mental-pressure or psychosomatic symptoms in employees/clinicians/ technicians. Invigorate and motivate them, to build-up the positive morale.

- Work as a team in organization, support each other. And encourage the employees/ clinicians/ technicians to communicate well about their sign, symptoms or any connection regarding COVID-19, to mitigate transmission.

- Posters (health and preventive information) should be placed at surroundings and common places of the official building to encourage hygiene, coughing and sneezing etiquettes and about self-isolation at home .

- Provide tissues and no-touch disposal receptacles for use by employees at their workplaces.

- Provide hand sanitizer in the workshop and allocate them at different places such as; meeting-rooms and counters for handhygiene.

- In compliance with government instructions, employees having coronavirus symptoms are advised not to come to the workspace.

- Use mask specially when talking to one another (to avoid the spread of droplets

\section{Recommendations for Clinicians}

Quality management in these days of epidemic should not be compromised, as previously there were over 1.9 million amputees and disables as reported by Amputee Coalition of America in 2006, now according to $\mathrm{WHO}$ and World Bank report ratio is increased upto 2 billion. So the practitioners should focus to manage quality which should not be by-passed as they are lacking rehabilitation and try to organize a service for home delivery of orthoses and prostheses. Moreover, patients are an integral part of health-care systems, therefore they should not be ignored specially in the matter of safety and the safety that ultimately make them healthy and mitigate their risk factors against respective pandemic disease. Following are some more recommendation points to be implemented by clinicians:

- Assign each practitioner for particular section or workspace to supervise and meet clinical needs. After an interval round practitioner should return directly to his room.

- Wear masks with face-shield, aprons or labcoats for precautions.

- Interact patients by maintaining feasible distance.

- When adjusting devices on patients, use each pair of glove on single each patient and remove them with proper donning and doffing techniques.

- Guide patients to take appointments and remind them to bring health certificates for confirmation.

- Tell patients to come alone or with only one helper. If elderly individual want his assistive device to repair, make sure send your relative or friend with the device.

- Aim to support patients in this difficult time of epidemic with care and respect.

- Make a ratio of your regular patients and divide them in such a way that the national rule of social-distancing don't be over-ruled. 
For example; if an organization has 50 regular patients, so divide them 10 respectively on week days.

- Clean the assistive devices to disinfect, before delivering or hand-overing to patients (use wipes or towels with Virucidal, Bactericidal, or Fungicidal to disinfect the surfaces of the device. These chemicals only disinfect when they are wet and left wet on the device for at least 4-minutes).

- Provide services such as, home-delivery of several assistive devices to gain the quality and to make isolation promised.

Performance and quality will be gained by a repeated cyclic process, which is given below:

\section{PDCA (Plan-Do-Check-Act)}

\section{Procedures:}

- Identify and adapt appropriate standards.

Methods:

- Decide the procedures for optimization.

- $\quad$ Prepare a plan to adopt safety measures.

- Guidethestaffwhowill helpinimplementations.

- Execute the procedures and record the data.

\section{Management Process:}

The key data regarding managing the procedures may include:

\section{- Personal data.}

- Health status of employee and patient as well.

- Psychosomatic analysis.

- Analyze functional condition of patient.

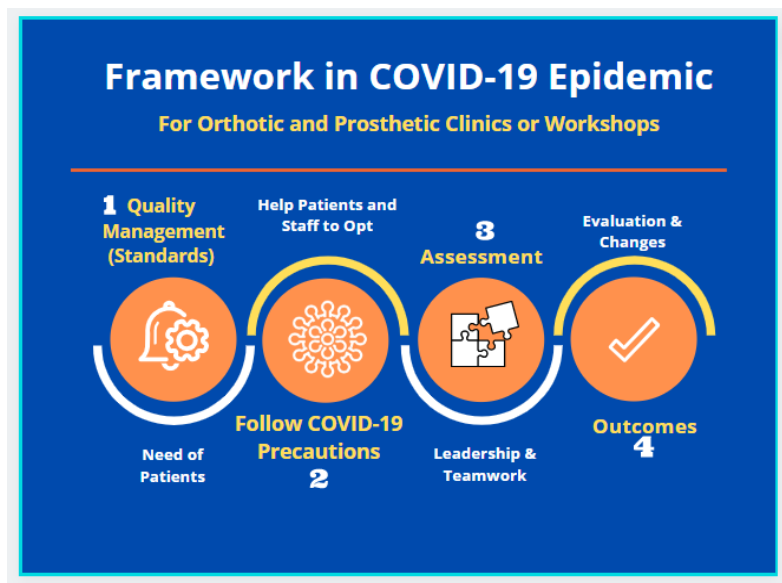

Figure 1: A working framework to be opt within Orthotic and Prosthetic workshops or clinics.
- Device details (See for repair or changes if needed).

\section{Recommendations for Technical-Staff}

\section{Instruments and Equipment's:}

- The plastic materials (polypropylene sheet, heat-guns, scales, inches-tape, goniometer etc.) should be sweep with detergents or disinfectants accordingly.

- The metallic instruments (scissors, verniercalliper, cutter, surform-blades etc.) should be sterilize in hot water or with sterilization oven.

- For the use of mutual machines like: oven, lathe-machine, vacuum system, grinders etc should be handled by a single person to avoid cross-contamination and cleaned as well with bleach and disinfectant.

- Assign each tool/instrument/equipment to each section or workspace of orthotics and prosthetics.

- Use gloves specially when dealing with a patients device, to avoid physical contact with its surface and clean it with alcohol swabs when returning.

\section{Recommendations for Non-Clinicians House-Keeping Staff:}

House-keeping staff within the official building should wear masks and gloves for self safety and precautions.

\section{Sanitation and Environmental Guidelines:}

- Regularly clean all often touched surfaces in the rehabilitation center, such as workshop, examination-room, counter-tops, waiting areas and doorknobs etc.

- Do not use supplemental disinfectant, other than routinely used cleansers.

- Use the disposable swabs/wipes on commonly used surfaces such as: doorknobs, keyboards, remote controls, desks, dispensers, waiting benches etc for employees/clinicians/ technicians before and after each use.

- Surfaces or objects should be disinfected by using chlorine or bleach.

- Ensure the accessibility of hand sanitizer (at least $70 \%$ alcohol).

- Glassware must be cleaned properly.

- Remove the non-essentials things from examination or casting room. 
- Disinfect wheel-chairs and crutches after every time it is used by patients.

- Use bleach as disinfectant for washrooms, entrance-walk throughs and common official gathering places (cafeteria, staff-rooms, meeting-rooms etc) after use or each activity.

- Sweep the floor with alcohol-based surface cleaner (such as 2-phenylethanol etc) routinely at divided intervals.

\section{Waste Management and Disinfection Policies:}

- Provide tissue papers or napkins on each panels for free use, to avoid rubbing nose with cuffs, clothes or hands.

- Dispose or incinerate the tissues or other consumable and disposable items within dustbins or according to the waste management SOP's of your organization.

- Gloves and masks should be shredded before disposal. 8

- $\quad$ Swabs should be burned. ${ }^{8}$

- $\quad$ Liquid infectious waste should be neutralized by chemicals and then waste them away. ${ }^{8}$

\section{Store Staff:}

According to Ministry of National Health Services, Regulation \& Coordination', recommended following precautions for the store staff and clients/ patients:

- The staff should wash hands with soap or use hand sanitizer (70\% alcoholic).

- Do not bleach the materials such as: steel, wood or metal, because they may be denatured or cause rusting.

- Make sure every individual sanitizes his hands before entering and leaving the store.

- Do not allow the coughing and sneezing customer/patient to enter the store, and allow them to enter one by one in store.

- Patients and salesperson should ensure the safe distance of 2 meter between each other.

- Each salesperson and receptionist must use gloves.

- The rest-room for store members should be disinfected daily and should be used with appropriate physical-distancing measure of 6 feet or 2 meters.

- $\quad$ Ensure the public display of notices promoting hand hygiene and other precautions.
- Ensure queue discipline, maintaining advised distance, outside and other premises of store.

- Store manager and staff must follow every updated instructions directed by the organization and strictly impose them.

\section{DISCUSSIONS}

As stated by Ephraim et al. ${ }^{10}$, limb loss is globally accepted as a serious public health issue, yet policies and programs are being developed to promote health and rehabilitation among disables but need more vast research-based knowledge.

World Health Organization and World Bank calculated the population of disables, which yielded the total percentage of disables were $37.5 \%$. And $37.5 \%$ out of $15 \%$ of entire population of world were physically disabled, which means 7 billion out of 2 billion were facing disability. While, now it is year 2020 and as a estimate the population of physical disables would have been grown upto 3 times if compared to study done first in year 2006.

Today, knowing about the COVID-19 pandemic and its effects no one is considering to propose recommendations regarding this field of healthcare, yet being neglected by WHO, who consider rehabilitation and disability its core sustainability goals. In order to, cater such large population of patients, it is important to open national and international organizations, who are mainly serving the disables in the region. Moreover, recommendations are suggested to opt as a supportive back to patients, administration of organizations, clinicians and assistive technology practitioners. The recommendations cover all

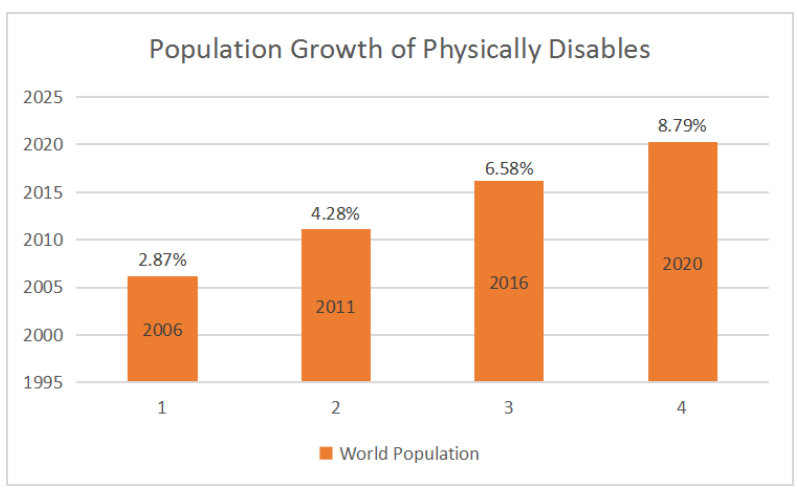

Figure 2: A Comparison of World Population and Growth of Physically Disabled Persons. 
aspects to contemplate the patients and regulate the organization. Regarding the regulation of an organization, a complete frame-work is suggested which will be surely be affective in implementation of initiatives.

On the other-hand, where we are concerned about patients, we should be committed to our worker's safety and health, specially those employees who are serving in these days of pandemic. As they are risking their lives for service of humanity and organization. So, organizational leaders should acknowledge and communicate widely about safety and health as a core function, and they should prioritize worker safety and health on the same level as quality of services and products. Additionally, mid-level supervisors and managers should actively participate in efforts that support worker safety, health, and well-being as middle management is the direct link between workers and upper management and plays a critical role in program success or failure. More broadly, build accountability into implementation of initiatives with accountability and leadership commitment to improved outcomes.

Hence, COVID-19 pandemic has caused major effects on health-care services, allied-health-care professionals, rehabilitation sector and assistive technology practitioners, which can not be easily recovered on a certain time period and losses may took years to step-down.

\section{CONCLUSION}

It is necessary to have preventive measures for every health-care branch specially orthotics and prosthetics. Today in the hustle of pandemic, patients are lacking rehabilitation, their proper assistance is being over-looked, their physical health is being subsided, and most importantly their quality of life is being impaired and immobile. Remaining at home is not just effecting their physical health but also their mental health gradually. To manage this social disaster of COVID-19 pandemic, we should implement these recommendations in respective field. We should opt these recommendations as a preparedness to tackle, assist and make patients needs meet properly. Moreover, where we are responsible for our patients we should also oversee our administrative team and worker's health and safety. Specially who are willing to work in this current situation of pandemic.

\section{REFERENCES}

1. Sun Z, Thilakavathy K, Kumar SS, He G, Liu SV. Potential factors influencing repeated SARS outbreaks in China. International Journal of Environmental Research and Public Health. 2020 Jan;17(5):1633. [GoogleScholar] [CrossRef] [https:// doi.org/10.3390/ijerph17051633]

2. She J, Jiang J, Ye L, Hu L, Bai C, Song Y. 2019 novel coronavirus of pneumonia in Wuhan, China: emerging attack and management strategies. Clinical and translational medicine. 2020 Dec;9(1):17. [GoogleScholar] [CrossRef] [FullText] [https://doi. org/10.1186/s40169-020-00271-z]

3. Heinemann AW, Bode RK, O'reilly C. Development and measurement properties of the Orthotics and Prosthetics Users' Survey (OPUS): a comprehensive set of clinical outcome instruments. Prosthetics and orthotics international. 2003 Jan 1;27(3):191-206. [GoogleScholar] [CrossRef] [FullText] [https://doi. org/10.1080/03393640308726682]

4. Salmani Nodooshan $H$, Koohi Booshehri $S$, Daneshmandi H, Choobineh AR. Ergonomic workplace assessment in orthotic and prosthetic workshops. Work. 2016 Jan 1;55(2):463-70. [GoogleScholar] [CrossRef] [FullText] [http://doi. org/10.3233/WOR-1828822]

5. World Health Organization. World report on disability 2011. World Health Organization; 2011. [GoogleScholar] [FullText]

6. Lee MP, Hudson $H$, Richards $R$, Chang $C C$, Chosewood LC, Schill AL. Fundamentals of total worker health approaches: essential elements for advancing worker safety, health, and well-being. [GoogleScholar] [CrossRef] [FullText]

7. National Institute of Health (Field Epidemiology \& Disease Surveillance Division); (2020). https://www. nih.org.pk/

8. Hegde V, Kulkarni RD, Ajantha GS. Biomedical waste management. Journal of Oral and Maxillofacial Pathology. 2007 Jan 1;11(1):5. [GoogleScholar] [CrossRef] [http://doi.org/10.4103/0973092X.33955]

9. Ministry of National Health Services, Regulation \& Coordination; (2020). (Document CODE: 09-02). [GoogleScholar]

10. Ephraim $P L$, Dillingham $T R$, Sector $M$, Pezzin $L E$, MacKenzie EJ. Epidemiology of limb loss and congenital limb deficiency: a review of the literature. Archives of physical medicine and rehabilitation. 2003 May 1;84(5):747-61. [GoogleScholar] [CrossRef] [http://doi.org/10.1016/S0003-9993(02)04932-8] 